\title{
Neurodevelopmental outcome at 2 years for preterm children born at 22 to 34 weeks' gestation in France in 2011: EPIPAGE-2 cohort study
}

Véronique Pierrat, ${ }^{1,2}$ Laetitia Marchand-Martin, ${ }^{1}$ Catherine Arnaud, ${ }^{3}$ Monique Kaminski, ${ }^{1}$
Matthieu Resche-Rigon, ${ }^{4}$ Cécile Lebeaux ${ }^{1}$ Florence Bodeau-Livinec, ${ }^{1,5}$ Andrei S Morgan, ${ }^{1}$
François Goffinet, ${ }^{1,6}$ Stéphane Marret, ${ }^{7,8}$ Pierre-Yves Ancel, ${ }^{1,9}$ and the EPIPAGE-2 writing group

\section{ABSTRACT}

OBJECTIVES

To describe neurodevelopmental outcomes at 2 years corrected age for children born alive at 22-26, 27-31, and 32-34 weeks' gestation in 2011, and to evaluate changes since 1997.

\section{DESIGN}

Population based cohort studies, EPIPAGE and EPIPAGE-2.

\section{SETTING}

FRANCE.

\section{PARTICIPANTS}

5567 neonates born alive in 2011 at 22-34 completed weeks' gestation, with 4199 survivors at 2 years corrected age included in follow-up. Comparison of outcomes reported for 3334 (1997) and 2418 (2011) neonates born alive in the nine regions participating in both studies.

\section{MAIN OUTCOME MEASURES}

Survival; cerebral palsy (2000 European consensus definition); scores below threshold on the neurodevelopmental Ages and Stages Questionnaire (ASQ; at least one of five domains below threshold) if completed between 22 and 26 months corrected age, in children without cerebral palsy, blindness, or deafness; and survival without severe or moderate neuromotor or sensory disabilities (cerebral palsy with Gross Motor Function Classification System levels 2-5,

\section{WHAT IS ALREADY KNOWN ON THIS TOPIC}

Survival of preterm neonates has increased worldwide, with a concomitant decrease in severe neonatal morbidities

Recent studies on neurodevelopmental outcomes of children born in the 2000s have focused on extremely preterm children, but outcomes of children born very and moderately preterm have rarely been reported

Identifying children at risk of later developmental delay who were born extremely, very, or moderately preterm is challenging

\section{WHAT THIS STUDY ADDS}

In France from 1997 to 2011, severe neonatal morbidities in children born preterm decreased, accompanied by a statistically significant increase in survival without severe or moderate neuromotor or sensory disabilities at age 2 years Despite improvements in neuromotor and sensory outcomes, a high number of children born before 34 weeks are at risk of developmental delay

Depending on gestational age, between half and one third of children born preterm will need formal developmental evaluation; using parental questionnaires as a first step approach to assess development may allow clinical resources to be focussed on those most likely to benefit unilateral or bilateral blindness or deafness). Results are given as percentage of outcome measures with $95 \%$ confidence intervals.

\section{RESULTS}

Among 5170 liveborn neonates with parental consent, survival at 2 years corrected age was $51.7 \%$ (95\% confidence interval $48.6 \%$ to $54.7 \%$ ) at $22-26$ weeks' gestation, $93.1 \%(92.1 \%$ to $94.0 \%)$ at $27-31$ weeks' gestation, and $98.6 \%$ (97.8\% to $99.2 \%)$ at $32-34$ weeks' gestation. Only one infant born at 22-23 weeks survived. Data on cerebral palsy were available for 3599 infants ( $81.0 \%$ of the eligible population). The overall rate of cerebral palsy at 24-26, 27-31, and $32-34$ weeks' gestation was $6.9 \%$ (4.7\% to $9.6 \%$ ), $4.3 \%$ (3.5\% to $5.2 \%$ ), and $1.0 \%$ (0.5\% to $1.9 \%$ ), respectively. Responses to the ASQ were analysed for 2506 children (56.4\% of the eligible population). The proportion of children with an ASQ result below threshold at 24-26, 27-31, and 32-34 weeks' gestation were $50.2 \%$ ( $44.5 \%$ to $55.8 \%$ ), $40.7 \%$ (38.3\% to $43.2 \%$ ), and $36.2 \%$ (32.4\% to $40.1 \%$ ), respectively. Survival without severe or moderate neuromotor or sensory disabilities among live births increased between 1997 and 2011, from 45.5\% (39.2\% to $51.8 \%$ ) to $62.3 \%$ ( $57.1 \%$ to $67.5 \%$ ) at 25 26 weeks' gestation, but no change was observed at 22-24 weeks' gestation. At 32-34 weeks' gestation, there was a non-statistically significant increase in survival without severe or moderate neuromotor or sensory disabilities $(P=0.61)$, but the proportion of survivors with cerebral palsy declined $(\mathrm{P}=0.01)$.

\section{CONCLUSIONS}

In this large cohort of preterm infants, rates of surviva and survival without severe or moderate neuromotor or sensory disabilities have increased during the past two decades, but these children remain at high risk of developmental delay.

\section{Introduction}

Survival of preterm babies has increased worldwide, with a concomitant decrease in severe neonatal morbidity. ${ }^{1-4}$ However, the risk of neurodevelopmental and behavioural disabilities remains high in children $^{5-10}$ and in adults who were born preterm. ${ }^{11} 12$ At extremely low gestations, ethical questions are crucial, and most recent national cohort studies have focused exclusively on extremely preterm birth. ${ }^{56813-15}$ Controversies over treatment decisions are described. ${ }^{16}$ During the past two decades, countries with active perinatal care at extremely low gestation (eg, USA, ${ }^{15}$ England, ${ }^{5}$ Sweden, ${ }^{6}$ ) have reported improvements in 
outcomes for periviable infants (infants born at 2225 weeks' gestation). Despite these improvements, survival without neurodevelopmental impairment at 2-2.5 years was $20 \%$ in the USA for infants born at 2224 weeks' gestation, ${ }^{15}$ and 34\% and 42\% in England ${ }^{5}$ and Sweden, ${ }^{6}$ respectively, for infants born at 2226 weeks' gestation. Results from countries without recommendations for active perinatal care at extremely low gestation have been less frequently reported. ${ }^{17}$ In absolute numbers, infants born very and moderately preterm represent a larger proportion of preterm births accounting for more children with motor, cognitive, or behavioural deficits and learning disabilities. ${ }^{1819}$ These populations of very and moderately preterm neonates have been poorly investigated, but knowledge of specific developmental domains affected at preschool age could lead to targeted intervention and prevention of later disabilities, as timely intervention has a positive influence on cognitive outcome in infancy. ${ }^{20}$ Updated information is therefore needed on outcomes for infants born at different gestational ages and in different settings to guide health policy, advise doctors in perinatal management, provide comprehensive information to facilitate parents' involvement in shared decision making, and benchmark outcomes. ${ }^{21}$

Developmental delay rather than survival is now recognised as the main problem in children born preterm. ${ }^{5} 61015$ Early identification of children at risk of later developmental difficulties may increase access to formal evaluation and subsequent intervention, potentially influencing the course of otherwise persistent difficulties. ${ }^{22}$ The Bayley Scales of Infant Development is usually the assessment of choice for neurodevelopmental evaluation between 18 and 30 months. ${ }^{5615}$ However, it is costly and time consuming, requires trained staff, and cannot be applied routinely to all children born preterm, particularly at more than 32 weeks' gestation where numbers are much greater. Alternative tools that can effectively screen for developmental delay are therefore needed. Parental questionnaires are increasingly popular to assess development, as they are easy to administer and interpret, have a short completion time, and can decrease medical expenditure. In addition, they may be used in the community, have the capacity to facilitate parental involvement, and enable clinicians to focus on those children suspected of having developmental delay and hence needing further developmental assessment. $^{23} 24$ The Ages and Stages Questionnaire (ASQ) is the most commonly used parent completed developmental screening test worldwide, and it is accepted by the American Academy of Paediatrics as a valid developmental screening tool ${ }^{25}$; it has been translated to, and validated in, French ${ }^{26}$ and there are arguments to support the cross cultural validity of the ASQ for other European countries. ${ }^{27}$ It could thus be useful for both large cohort studies and routine followup as a first step approach to increase early detection of neurodevelopmental delay. However, its use in a national population of preterm children has never been evaluated.
The 2011 EPIPAGE-2 study is a national cohort study, designed to investigate outcomes and their changes over the past 15 years for children born from 22-34 weeks' gestation. ${ }^{28}$ In the original EPIPAGE cohort, data were collected on all very preterm births in nine French regions during $1997^{29}$ and the surviving children were assessed at age 5 and 8 years. ${ }^{18} 19$ Substantial improvements in neonatal survival, accompanied by a large reduction in severe neonatal morbidity, have already been reported, although survival remained low before 25 weeks' gestation compared with other countries. $^{2}$ In the present study, we analysed neuromotor, sensory, and neurodevelopmental outcomes at 2 years corrected age, based on medical and parental evaluation of development using ASQ, for children born alive from 22-34 weeks' gestation included in the EPIPAGE-2 cohort. We compared rates of survival, survival without neuromotor and sensory disabilities, and cerebral palsy in children born alive during 1997.

\section{Methods}

\section{Study design and population}

EPIPAGE-2 is a prospective national population based cohort scheduled to follow preterm children up to the age of 12 years. Infants born at 22-34 completed weeks' gestation in all maternity units in 25 French regions ( 21 of the 22 metropolitan regions and all four overseas regions) were eligible for inclusion. The only region that did not participate accounted for $2 \%$ of births in France in 2011. ${ }^{28}$ Recruitment took place at birth and children were included in the study and data collected only after families had received information and agreed to participate in the study. Hence, for children whose parents declined participation, only status at birth, mortality, and limited perinatal data were available. The study began on 28 March 2011. Infants born at 22-26 weeks' gestation were recruited during an eight month period, those born at 27-31 weeks' gestation during a six month period, and those born at 32-34 weeks' gestation during a five week period. ${ }^{28}$ All survivors were enrolled for longitudinal follow-up and included in the study at 2 years corrected age if parents consented.

\section{Data collection and evaluation methods}

Data for children at 2 years corrected age were collected by using two standardised questionnaires: one completed by the referring doctor and the other by the parents.

\section{Cerebral palsy and sensory deficits}

We extracted data for cerebral palsy from the medical questionnaire, including information on major developmental steps (head control, sitting, standing, walking, and quality of gait), trunk and limb tone (low, normal, increased), and other abnormal neurological signs (see web appendix 1). Questions were pre-coded to minimise the risk of ambiguous answers. Questionnaires were similar in 1997 and 2011 to facilitate comparisons. Cerebral palsy was 
defined according to the diagnostic criteria of the Surveillance of Cerebral Palsy in Europe (SCPE) network, ${ }^{30}$ and motor ability was graded by using the five level Gross Motor Function Classification System (GMFCS). ${ }^{31}$ We also report the proportion of children with ambulatory cerebral palsy, defined as those with cerebral palsy who were walking at 2 years of age, with or without aids. Paediatricians in charge of routine follow-up performed the examinations. If a routine follow-up was unavailable, parents were asked to get their practitioner of choice to complete the medical questionnaire to ensure higher follow-up rates. Three of the authors (VP, FBL, and SM) separately reviewed ambiguous cases, with agreement on discrepancies reached in a consensus meeting. Data on vision and hearing were obtained from medical reports available during the medical examination. In cases of blindness, visual impairment was classified as severe (bilateral) or moderate (unilateral). Squinting or the need for glasses was also recorded. In cases of deafness, auditory impairment was classified as severe (bilateral) or moderate (unilateral). Severe neuromotor or sensory disabilities included any of GMFCS level 3-5 cerebral palsy or severe visual or auditory impairment; moderate disability included GMFCS level 2 cerebral palsy with or without moderate visual or auditory impairment. Children without severe or moderate neuromotor or sensory disabilities were classified as having no or minor neuromotor or sensory disabilities.

\section{Overall neurodevelopment}

The child's development was assessed with the second version of the 24 month Ages and Stages Questionnaire (ASQ) validated in France ${ }^{26}$ and completed by parents; data were analysed if completed between 22 and 26 months corrected age in children without cerebral palsy, deafness, blindness, or severe congenital brain malformations. Each questionnaire includes 30 items covering five developmental domains: communication abilities, gross motor skills, fine motor skills, problem solving abilities, and personal-social skills. Items are scored on a three point scale depending on whether the child performs the task: yes (10 points), sometimes ( 5 points), or not yet (0 points). Responses are summed to give a score of 0 to 60 for each domain and an overall maximum ASQ score of 300 points. Analyses were based on domain specific scores, using established screening cut-off points: an ASQ score below threshold was defined as a score lower than 2 standard deviations from the mean on any of the five domains. ${ }^{24}$ We also report the number and nature of domains with scores below threshold.

Other major disabilities at 2 years corrected age

Major disabilities affecting respiratory or gastrointestinal systems were recorded. Respiratory disability was defined as the need for continuous respiratory support or oxygen and gastrointestinal disability as the need for parenteral nutrition or enteral feeding through a nasogastric tube or gastrostomy, or both. ${ }^{32}$

\section{Comparison of 1997 and 2011 EPIPAGE cohorts}

Children eligible for comparison were those born alive at 22-34 weeks' gestation from the 1997 and 2011 cohorts in the nine regions participating in both studies. ${ }^{29}$ Outcome measures at 2 years corrected age were rates of survival, survival without severe or moderate neuromotor or sensory disabilities among live births, and cerebral palsy among survivors.

\section{Data management and statistics}

Results among live births and at 2 years are presented by gestational age grouping (22-26, 27-31, combined 2231 , and 32-34 weeks' gestation for survival analyses; 24-26, 27-31, combined 24-31, and 32-34 weeks' gestation for disability analyses), and by week for those born at 22-26 weeks' gestation. Firstly, summary data on maternal characteristics (maternal age, birth outside of France, and parents' socioeconomic status), obstetric (multiple pregnancy, antenatal steroids, and caesarean section), and neonatal factors (sex, small for gestational age, inborn status, surfactant, postnatal steroids, severe neonatal morbidities, and breast milk at discharge) are presented for children whose parents gave consent at birth and for survivors included in the study at 2 years corrected age; data were compared with those who did not participate in the initial study or were lost to follow-up. Socioeconomic status was defined as the highest occupational status of the mother and father, or mother only if a single parent, small for gestational age as birth weight $<10$ th centile for gestational age and sex based on French "EPOPé" intrauterine growth curves, ${ }^{33}$ and severe neonatal morbidities as severe bronchopulmonary dysplasia, necrotising enterocolitis (Bell stages 2-3), severe retinopathy of prematurity stage $>3$, or any of the following severe cerebral abnormalities on cranial ultrasonography: intraventricular haemorrhage grade III or IV or cystic periventricular leukomalacia. ${ }^{2}$ Secondly, for children examined at 2 years corrected age, percentages of cerebral palsy, visual and hearing impairments, and ASQ below threshold are presented. Thirdly, among live births, rates of total survival are reported for all cases, and survival without severe or moderate neuromotor and sensory disabilities for all cases after multiple imputation to account for selective dropouts and missing information at 2 years corrected age; among survivors, rates are reported for both complete cases and all cases after multiple imputation. Multiple imputation was performed as a sensitivity analysis. Missing data were imputed by chained equations using the SAS "MI" procedure. ${ }^{34}$ Imputation model variables included both those potentially predicting non-response and/or outcomes (gestational age, maternal age and country of birth, parity, parental socioeconomic status, antenatal steroids, caesarean section, multiple pregnancy, sex, small for gestational age, severe congenital brain malformation, inborn status, surfactant, postnatal steroids, severe neonatal morbidities, use of breast milk at discharge), and outcomes (cerebral palsy, neuromotor or sensory disabilities, and ASQ). For 
ASQ, missing domains (defined as binary variables (yes/no) for a score below threshold in each of the five domains) were separately imputed to account for partially completed questionnaires. Overall ASQ score was then estimated using the domain specific imputed datasets for infants without cerebral palsy, deafness, blindness, or severe congenital anomalies. Socioeconomic data were imputed using multinomial models. Other variables with missing data, all binary, were imputed using logistic regression. We generated 50 independent imputed datasets with 30 iterations each. Estimates were pooled according to Rubin's rule. ${ }^{35}$ Further details are available in web appendix 2. Fourthly, to document trends over time, we compared 1997 and 2011 rates of survival, survival without severe or moderate neuromotor or sensory disabilities among live births, and cerebral palsy among survivors and calculated the difference between 1997 and 2011 adjusted for baseline factors that may influence outcomes (gestational age, small for gestational age, sex, and multiple pregnancy status). Risk differences were estimated using a binomial model with identity

Liveborn infants at 22-34 completed weeks' gestation $(n=5567)$

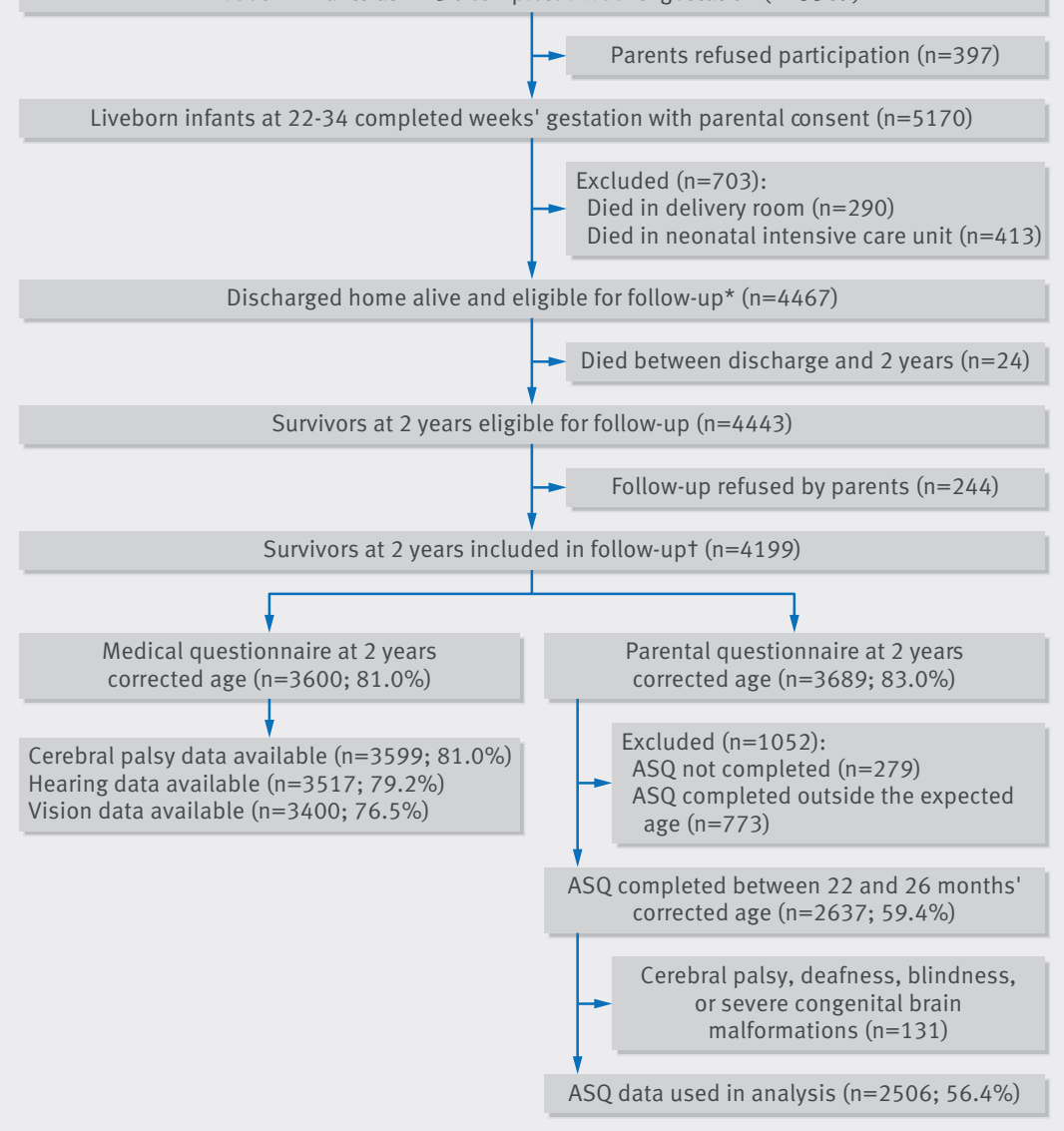

Fig 1 | Flowchart of study population: EPIPAGE-2 cohort at 2 years corrected age. $A S Q=A g e s$ and Stages Questionnaire. Percentages in parentheses are number of events/number of survivors at 2 years eligible for the study $(n=4443)$. *No survivors at 22 weeks and only one survivor at 23 weeks and six days. tOf the 4199 survivors at 2 years included in follow-up, 2545 had data available for both cerebral palsy and ASQ between 22 and 26 months corrected age, cerebral palsy data only were available for 1054, ASQ data only for 92, and no data were available for 508 children link. Cohort data were obtained from the entire year in 1997 and from 28 March 2011 to 31 December 2011. Analyses for 1997 were run for the entire year and then separately for April to December. Results did not differ, and thus 1997 data are presented for the whole year. To better understand the link between the evolution of outcomes and variations in practice, we compared the maternal characteristics and obstetric and neonatal factors of the 1997 and 2011 populations. Finally, factors associated with cerebral palsy or an ASQ score below threshold were studied for complete cases by using multiple logistic regression models. Variables entered into the models were gestational age, sex, single or multiple pregnancy status, small for gestational age, and parental socioeconomic status.

Percentages are given with their exact 95\% binomial confidence intervals, and medians with interquartile ranges. For analyses performed on the overall cohort, we used weighted percentages and gestational age adjustments in the multivariable analyses to account for differences in sampling times between gestational age groups. We compared groups of infants using the $\chi^{2}$ test. All tests were two sided; $\mathrm{P}<0.05$ was considered statistically significant. Statistical analyses were performed using SAS v9.4 software.

\section{Patient involvement}

Patients were not involved in setting the research question or the outcome measures, nor were they involved in developing plans for design of the study. Parents showed overwhelming support for the study through high follow-up rates and by providing testimonials (displayed on the EPIPAGE-2 website at http://epipage2.inserm.fr/index.php/fr/cote-parents/ temoignages). EPIPAGE-2 maintains contact with parents in the cohort through letters, newsletters, and its website. National parents' associations assisted with the dissemination of the results.

\section{Results}

\section{EPIPAGE-2: neurodevelopmental outcomes and} overall survival at 2 years corrected age

\section{Population}

Parental consent was obtained for inclusion of 5170 of 5567 liveborn babies between 22 and 34 weeks' gestation in the EPIPAGE-2 study. All survivors ( $n=4467)$ were enrolled for longitudinal follow-up; 24 died postdischarge and the parents of 244 declined further participation. Thus, 4199 children were included in the follow-up study. Among these 4199 children, medical questionnaires were available for $3600(81.0 \%$ of all children) and parental questionnaires for 3689 (83.0\% of all children) (fig 1). Overall, 148 neonates were born alive at 22-23 weeks' gestation and all but one died in the neonatal period. This survivor was born at 23 weeks' gestation and six days and was therefore included with those born at 24 weeks' gestation.

Web appendix 3 shows the comparisons between children with and without parental consent at birth for participation, as well as children with and without cerebral palsy or ASQ data available. 
Neonates whose parents refused participation were born more frequently at 32-34 weeks' gestation and to mothers of lower socioeconomic status. Compared with responders, children with unavailable cerebral palsy or ASQ data were more frequently born at 3234 weeks' gestation, after a singleton pregnancy, to younger mothers, mothers born outside France, or to mothers of a lower socioeconomic status, and were less frequently fed breast milk at discharge; however, the main neonatal outcomes did not differ between groups. Web appendix 4 shows the characteristics of children with data about cerebral palsy status according to gestational age group.

\section{Cerebral palsy and sensory outcomes}

Medical examinations were performed at a median of 24.2 months corrected age (interquartile range 23.125.7 ) and by a paediatrician in $88.0 \%, 80.2 \%$, and $59.8 \%$ of children born at 24-26, 27-31, and 32-34 weeks' gestation, respectively. Information on cerebral palsy was available from 3599/3600 questionnaires (2714 and 885 for children born at 24-31 and 3234 weeks' gestation, respectively). Cerebral palsy was diagnosed in 137 children: bilateral spastic cerebral palsy in 120 (weighted \%, 82.3\%), unilateral spastic cerebral palsy in 15 (weighted \%, 16.5\%), and dyskinetic or unclassifiable cerebral palsy in 2 (weighted \%, 1.2\%). The overall rate of cerebral palsy was $4.6 \%$ at 24-31 weeks' gestation, decreasing from $6.9 \%$ to $4.3 \%$ between $24-26$ and $27-31$ weeks' gestation. At 32-34 weeks' gestation, the cerebral palsy rate was $1.0 \%$ (table 1). Among those with cerebral palsy, $15 / 31$ (48.4\%), 51/97 (52.6\%), and $7 / 9$ $(77.8 \%)$ at 24-26, 27-31, and 32-34 weeks' gestation, respectively, were ambulatory forms of cerebral palsy. Severe auditory or visual impairment was reported in fewer than $1 \%$ of children included in the cohort. The proportion of children wearing glasses decreased with increasing gestational age.

\section{Neurodevelopmental outcome}

Parental questionnaires were collected at a median of 24.3 months corrected age (interquartile range 23.5-26.3). Among the 3689 parental questionnaires available, ASQ analysis was possible for 2637 children (59.4\% of all children). In total, 131 questionnaires were excluded because of cerebral palsy, deafness or blindness $(n=121)$, or severe congenital brain malformations ( $\mathrm{n}=10)$, leaving 2506 questionnaires in the complete case analysis (1884 and 622 for children born at 24-31 and 32-34 weeks' gestation, respectively). Median ASQ scores increased from 223 at 24-26 weeks' gestation to 235 at 32-34 weeks' gestation (table 1). An ASQ score below threshold was observed in 50.2\%, $40.7 \%$, and $36.2 \%$ of children born at $24-26,27-31$, and 32-34 weeks' gestation, respectively; 7.7\%, 3.8\%, and $1.8 \%$ of these respective groups had a score below threshold in 4-5 ASQ domains. Web appendix 8 shows the median total scores by number of domains below threshold. The domains most frequently scoring below threshold were communication and personal-social in all gestational age groups. Proportions of children scoring below the threshold in either of these domains decreased with increasing gestational age but were still $17.8 \%$ and $13.3 \%$, respectively, at 32-34 weeks' gestation. Although children with cerebral palsy were excluded, $16.6 \%$ of children born at 24-26 weeks' gestation scored below the threshold in the gross motor domain compared with 5.1\% at 32-34 weeks' gestation.

\section{Other major disabilities}

Nine children out of 2667 with available data born at 24 to 31 weeks' gestation $(0.3 \%, 95 \%$ confidence interval $0.1 \%$ to $0.6 \%$ ) still needed oxygen at 2 years corrected age, 28 of $2660(1.0 \%, 0.6 \%$ to $1.4 \%)$ received enteral nutrition by tube or gastrostomy, and 3 out of $2652(0.1 \%, 0.0 \%$ to $0.3 \%)$ received parenteral nutrition. The proportion of children fed by tube or gastrostomy was $2.7 \%(1.4 \%$ to $4.7 \%)$ at $24-26$ weeks' gestation (12/447) and $0.7 \%(0.4$ to 1.2$)$ at 27 31 weeks' gestation (16/2218). Overall, 11 children out of 2470 with data available for all variables $(0.4 \%$, $0.2 \%$ to $0.7 \%$ ) had respiratory or gastrointestinal disabilities associated with cerebral palsy and/or deafness or blindness. Fewer than $0.5 \%$ of children born at 32-34 weeks' gestation (4/885) had respiratory or gastrointestinal disabilities.

Overall survival at 2 years corrected age and dropout analyses

Among live births, survival at 2 years corrected age increased with increasing gestational age and, after multiple imputation, survival without severe or moderate neuromotor and sensory disabilities was $48.5 \%, 90.0 \%$, and $97.5 \%$ at 22-26, 27-31, and 3234 weeks' gestation, respectively (table 2). Among survivors at 2 years corrected age, rates of cerebral palsy were only slightly modified after multiple imputation, but rates of ASQ scores below threshold increased in all gestational age groups after multiple imputation. Web appendix 5 presents the outcomes for children born at 24-26 weeks' gestation by gestational week.

\section{Comparison of the 1997 and 2011 EPIPAGE cohorts (nine regions)}

Neonates born alive at 22-34 weeks' gestation in the nine regions participating in both EPIPAGE studies totalled 3334 in 1997 and 2418 in 2011; 2262 (1997) and 1696 (2011) were alive at 2 years corrected age with outcome data available (table 3). Followup rates at 2 years were $79.0 \%$ in 1997 and 82.2\% in 2011. No infant born at 22-23 weeks' gestation survived in these nine regions in either period. After adjustment for baseline characteristics, for children born at 22-31 weeks' gestation, survival increased by $6.0 \%$ (95\% confidence interval, $3.5 \%$ to $8.5 \%$ ), and survival without neuromotor or sensory impairment by $7.2 \%(4.7 \%$ to $9.8 \%)$; in children born at $24-31$ weeks' gestation, cerebral palsy decreased by $3.3 \%$ (1.6\% to $5.0 \%$ ). Changes between the two periods for 


\begin{tabular}{|c|c|c|c|c|c|c|c|c|c|}
\hline \multirow[b]{2}{*}{ Variables } & \multicolumn{2}{|c|}{ 24-31 weeks* } & \multicolumn{2}{|c|}{ 24-26 weeks* } & \multicolumn{2}{|l|}{ 27-31 weeks } & \multicolumn{2}{|l|}{$32-34$ weeks } & \multirow[t]{2}{*}{$P$ value } \\
\hline & $\begin{array}{l}\text { No of } \\
\text { events/ } \\
\text { No in group }\end{array}$ & $\%(95 \% \mathrm{Cl})$ & $\begin{array}{l}\text { No of } \\
\text { events/ } \\
\text { No in group }\end{array}$ & $\%(95 \% \mathrm{Cl})$ & $\begin{array}{l}\text { No of } \\
\text { events/ } \\
\text { No in group }\end{array}$ & $\%(95 \% \mathrm{Cl})$ & $\begin{array}{l}\text { No of } \\
\text { events/ } \\
\text { No in group }\end{array}$ & $\%(95 \% \mathrm{Cl})$ & \\
\hline Cerebral palsy & $128 / 2714$ & 4.6 (3.9 to 5.5$)$ & $31 / 450$ & 6.9 (4.7 to 9.6$)$ & $97 / 2264$ & $4.3(3.5$ to 5.2$)$ & $9 / 885$ & $1.0(0.5$ to 1.9$)$ & $<0.001$ \\
\hline \multicolumn{10}{|l|}{ GMFCS level: } \\
\hline 5 & $8 / 2714$ & 0.3 (0.1 to 0.6$)$ & $3 / 450$ & 0.7 (0.1 to 1.9$)$ & $5 / 2264$ & $0.2(0.1$ to 0.5$)$ & $0 / 885$ & $0.0(\mathrm{NA})$ & \\
\hline 3 or 4 & $24 / 2714$ & $0.9(0.6$ to 1.3$)$ & $5 / 450$ & 1.1 (0.4 to 2.6$)$ & $19 / 2264$ & $0.8(0.5$ to 1.3$)$ & $0 / 885$ & $0.0(\mathrm{NA})$ & \\
\hline 2 & $39 / 2714$ & $1.4(1.0$ to 1.9$)$ & $12 / 450$ & $2.7(1.4$ to 4.6$)$ & $27 / 2264$ & $1.2(0.8$ to 1.7$)$ & $3 / 885$ & $0.3(0.1$ to 1.0$)$ & \\
\hline 1 & $57 / 2714$ & 2.1 (1.6 to 2.7$)$ & $11 / 450$ & $2.4(1.2$ to 4.3$)$ & $46 / 2264$ & $2.0(1.5$ to 2.7$)$ & $6 / 885$ & $0.7(0.2$ to 1.5$)$ & \\
\hline \multicolumn{10}{|l|}{ Hearing } \\
\hline Deafness: & $19 / 2651$ & 0.7 (0.4 to 1.1$)$ & $6 / 442$ & $1.4(0.5$ to 2.9$)$ & $13 / 2209$ & $0.6(0.3$ to 1.0$)$ & 4/866 & 0.5 (0.1 to 1.2$)$ & 0.28 \\
\hline Bilateral & $13 / 2651$ & $0.5(0.2$ to 0.8$)$ & $6 / 442$ & $1.4(0.5$ to 2.9$)$ & $7 / 2209$ & $0.3(0.1$ to 0.7$)$ & $4 / 866$ & 0.5 (0.1 to 1.2$)$ & \\
\hline Unilateral & $6 / 2651$ & $0.2(0.1$ to 0.5$)$ & $0 / 442$ & $0.0(N A)$ & $6 / 2209$ & $0.3(0.1$ to 0.6$)$ & $0 / 866$ & $0.0(\mathrm{NA})$ & \\
\hline \multicolumn{10}{|l|}{ Vision } \\
\hline Blindness: & $10 / 2553$ & $0.4(0.2$ to 0.7$)$ & $3 / 421$ & $0.7(0.1$ to 2.1$)$ & $7 / 2132$ & $0.3(0.1$ to 0.7$)$ & $2 / 847$ & $0.2(0.0$ to 0.9$)$ & 0.51 \\
\hline Bilateral & $5 / 2553$ & $0.2(0.1$ to 0.4$)$ & $2 / 421$ & $0.5(0.1$ to 1.7$)$ & $3 / 2132$ & $0.1(0.0$ to 0.4$)$ & $1 / 847$ & 0.1 (0.0 to 0.7$)$ & \\
\hline Unilateral & $5 / 2553$ & $0.2(0.1$ to 0.5$)$ & $1 / 421$ & 0.2 (0.0 to 1.3$)$ & $4 / 2132$ & $0.2(0.1$ to 0.5$)$ & $1 / 847$ & 0.1 (0.0 to 0.7$)$ & \\
\hline Squinting $\ddagger$ & $152 / 2533$ & 5.9 (5.1 to 6.9) & $30 / 416$ & $7.2(4.9$ to 10.1$)$ & $122 / 2117$ & $5.8(4.8$ to 6.8$)$ & $30 / 840$ & $3.6(2.4$ to 5.1$)$ & 0.003 \\
\hline Wearing glasses $\ddagger$ & $180 / 2527$ & $7.0(6.1$ to 8.1$)$ & $38 / 418$ & $9.1(6.5$ to 12.3$)$ & $142 / 2109$ & $6.7(5.7$ to 7.9$)$ & $35 / 842$ & $4.2(2.9$ to 5.7$)$ & $<0.001$ \\
\hline \multicolumn{10}{|l|}{$\begin{array}{l}\text { Neuromotor or } \\
\text { sensory } \\
\text { disabilities§: }\end{array}$} \\
\hline Severe & $45 / 2524$ & 1.7 (1.3 to 2.3$)$ & $12 / 420$ & 2.9 (1.5 to 4.9$)$ & $33 / 2104$ & $1.6(1.1$ to 2.2$)$ & $5 / 834$ & $0.6(0.2$ to 1.4$)$ & $<0.001$ \\
\hline Moderate & $48 / 2524$ & 1.8 (1.4 to 2.5$)$ & $13 / 420$ & 3.1 (1.7 to 5.2$)$ & $35 / 2104$ & 1.7 (1.2 to 2.3$)$ & $3 / 834$ & 0.4 (0.1 to 1.0$)$ & \\
\hline $\begin{array}{l}\text { None or minor } \\
\text { disabilities }\end{array}$ & $2431 / 2524$ & 96.4 (95.6 to 97.1) & $395 / 420$ & $94.0(91.3$ to 96.1$)$ & $2036 / 2104$ & 96.8 (95.9 to 97.5) & $826 / 834$ & 99.0 (98.1 to 99.6) & \\
\hline \multicolumn{10}{|l|}{ ASQף: } \\
\hline $\begin{array}{l}\text { Median } \\
\text { (interquartile } \\
\text { range) total } \\
\text { ASQ score }\end{array}$ & 1884 & $229(199-255)$ & 313 & $223(185-250)$ & 1571 & $230(200-255)$ & 622 & $235(205-260)$ & $<0.001$ \\
\hline $\begin{array}{l}\text { ASQ score } \\
\text { below thresh- } \\
\text { old }{ }^{\star \star}\end{array}$ & $797 / 1884$ & 42.0 (39.7 to 44.2$)$ & $157 / 313$ & $50.2(44.5$ to 55.8$)$ & $640 / 1571$ & 40.7 (38.3 to 43.2$)$ & $225 / 622$ & $36.2(32.4$ to 40.1$)$ & $<0.001$ \\
\hline \multicolumn{10}{|l|}{$\begin{array}{l}\text { No of domains } \\
\text { below threshold: }\end{array}$} \\
\hline 0 & $1087 / 1884$ & 58.0 (55.8 to 60.3$)$ & $156 / 313$ & 49.8 (44.2 to 55.5) & $931 / 1571$ & $59.3(56.8$ to 61.7$)$ & $397 / 622$ & 63.8 (59.9 to 67.6$)$ & $<0.001$ \\
\hline 1 & $441 / 1884$ & $23.4(21.5$ to 25.4$)$ & $76 / 313$ & 24.3 (19.6 to 29.4) & $365 / 1571$ & $23.2(21.2$ to 25.4$)$ & $139 / 622$ & 22.3 (19.1 to 25.8$)$ & \\
\hline 2 & $171 / 1884$ & $8.9(7.7$ to 10.3$)$ & $38 / 313$ & 12.1 (8.7 to 16.3$)$ & $133 / 1571$ & $8.5(7.1$ to 10.0$)$ & $51 / 622$ & $8.2(6.2$ to 10.6$)$ & \\
\hline 3 & $101 / 1884$ & $5.3(4.4$ to 6.4$)$ & $19 / 313$ & $6.1(3.7$ to 9.3$)$ & $82 / 1571$ & $5.2(4.2$ to 6.4$)$ & $24 / 622$ & $3.9(2.5$ to 5.7$)$ & \\
\hline 4 or 5 & $84 / 1884$ & 4.3 (3.4 to 5.3$)$ & $24 / 313$ & $7.7(5.0$ to 11.2$)$ & $60 / 1571$ & $3.8(2.9$ to 4.9$)$ & $11 / 622$ & 1.8 (0.9 to 3.1$)$ & \\
\hline \multicolumn{10}{|l|}{ By domain: } \\
\hline Communication & $484 / 1884$ & 25.3 (23.4 to 27.4$)$ & $106 / 313$ & $33.9(28.6$ to 39.4$)$ & $378 / 1571$ & 24.1 (22.0 to 26.3) & $111 / 622$ & 17.8 (14.9 to 21.1$)$ & $<0.001$ \\
\hline Gross motor & $204 / 1884$ & $10.6(9.2$ to 12.0$)$ & $52 / 313$ & 16.6 (12.7 to 21.2) & $152 / 1571$ & $9.7(8.3$ to 11.2$)$ & $32 / 622$ & $5.1(3.5$ to 7.2$)$ & $<0.001$ \\
\hline Fine motor & $211 / 1884$ & $11.2(9.8$ to 12.7$)$ & $38 / 313$ & 12.1 (8.7 to 16.3$)$ & $173 / 1571$ & $11.0(9.5$ to 12.7$)$ & $65 / 622$ & $10.5(8.2$ to 13.1$)$ & 0.75 \\
\hline Problem solving & $217 / 1884$ & 11.5 (10.1 to 13.0$)$ & $40 / 313$ & $12.8(9.3$ to 17.0$)$ & $177 / 1571$ & $11.3(9.7$ to 12.9$)$ & $68 / 622$ & $10.9(8.6$ to 13.7$)$ & 0.69 \\
\hline Personal-social & $334 / 1884$ & 17.4 (15.7 to 19.2$)$ & $78 / 313$ & $24.9(20.2$ to 30.1$)$ & $256 / 1571$ & 16.3 (14.5 to 18.2 ) & $83 / 622$ & 13.3 (10.8 to 16.3$)$ & $<0.001$ \\
\hline
\end{tabular}

GMFCS=Gross Motor Function Classification System; NA=not applicable.

Denominators vary according to number of missing data for each variable. Percentages are weighted to account for differences in sampling process between gestational age groups. Data are presented by gestational age grouping: 24-26 and 27-31 (both italicised), combined 24-31, and 32-34 weeks' gestation.

*Including one survivor born at 23 weeks and six days. Percentages are weighted to account for differences in sampling process between gestational age groups.

tComparison between gestational age groups 24-26 weeks, 27-31 weeks, and 32-34 weeks.

¥For children without blindness.

$\S$ Severe or moderate neuromotor or sensory disability: severe=cerebral palsy GMFCS levels 3-5 and/or bilateral deafness and/or bilateral blindness; moderate=cerebral palsy GMFCS level-2 and/ or unilateral deafness and/or unilateral blindness. Seven infants had associated severe or moderate cerebral palsy and sensory disabilities.

IInfants with cerebral palsy, deafness, blindness, or severe congenital anomalies were excluded ( $n=131$ )

${ }_{\star \star \star}$ For each domain, a score lower than 2 standard deviations from the mean, using established screening cut-off points (Squire $2009^{24}$ ) was reported. If a score was below threshold in at least one domain, the global ASQ was considered below threshold.

Overall, the rate of survivors with no or minor neuromotor or sensory disabilities increased from $94.0 \%$ at $24-26$ weeks' gestation to $96.8 \%$ at $27-31$ weeks' gestation and $99.0 \%$ at $32-34$ weeks' gestation.

both survival, survival without neuromotor or sensory disabilities, and rates of cerebral palsy in survivors were not statistically significant for children born at 24 weeks' gestation, but noticeable improvements were seen at 25-26 weeks and, to a lesser extent, at 27-31 weeks. Web appendix 6 presents the data for survival and survival without neuromotor or sensory disabilities by gestational weeks. At 32-34 weeks' gestation, the rate of cerebral palsy declined by 3.3\% (0.7\% to 5.9\%), but survival and survival without severe neuromotor or sensory impairment were similar.

Table 4 shows the changes between 1997 and 2011 in maternal characteristics and obstetric and neonatal factors. In 2011, mothers were older and parents were 


\begin{tabular}{|c|c|c|c|c|c|}
\hline \multirow[b]{2}{*}{ Variables } & \multirow[b]{2}{*}{ Data analysis } & \multicolumn{4}{|l|}{$\%(95 \% \mathrm{Cl})$} \\
\hline & & 22-31 weeks & $22-26$ weeks & 27-31 weeks & 32-34 weeks \\
\hline \multicolumn{6}{|l|}{ Live births } \\
\hline Survival at 2 years corrected age* & Complete cases & $84.3(83.2$ to 85.4$)$ & 51.7 (48.6 to 54.7$)$ & 93.1 (92.1 to 94.0) & 98.6 (97.8 to 99.2$)$ \\
\hline $\begin{array}{l}\text { Survival without neuromotor or sensory } \\
\text { disabilities at } 2 \text { years corrected aget }\end{array}$ & Multiple imputation & $81.2(79.9$ to 82.4$)$ & $48.5(45.4$ to 51.6$)$ & $90.0(88.8$ to 91.1$)$ & 97.5 (96.4 to 98.5$)$ \\
\hline \multicolumn{6}{|l|}{ Survivors at 2 years corrected age $\neq$} \\
\hline \multirow[t]{2}{*}{ Cerebral palsy } & Complete cases & $4.6(3.9$ to 5.5$)$ & $6.9(4.7$ to 9.6$)$ & $4.3(3.5$ to 5.2$)$ & $1.0(0.5$ to 1.9$)$ \\
\hline & Multiple imputation & $4.8(4.0$ to 5.6$)$ & $7.2(4.9$ to 9.6$)$ & $4.4(3.6$ to 5.3$)$ & $1.1(0.4$ to 1.7$)$ \\
\hline \multirow[t]{2}{*}{ ASQ score below threshold§ } & Complete cases & 42.0 (39.7 to 44.2$)$ & $50.2(44.5$ to 55.8$)$ & $40.7(38.3$ to 43.2$)$ & $36.2(32.4$ to 40.1$)$ \\
\hline & Multiple imputation & $47.8(45.5$ to 50.2$)$ & $55.8(50.8$ to 60.9$)$ & $46.7(44.2$ to 49.2$)$ & 42.7 (38.7 to 46.7$)$ \\
\hline \multicolumn{6}{|c|}{$\begin{array}{l}\text { Total percentages are weighted to account for differences in sampling process between gestational age groups. Data are presented by gestational age grouping: } 22-26 \text { and } 27-31 \text { (both } \\
\text { italicised), combined 24-31, and 32-34 weeks' gestation. } \\
\text { *No missing data for survival at } 2 \text { years. } \\
\text { †Severe or moderate neuromotor or sensory disability: severe=cerebral palsy GMFCS levels } 3-5 \text { and/or bilateral deafness and/or bilateral blindness; moderate=cerebral palsy GMFCS level } 2 \text { and/ } \\
\text { or unilateral deafness and/or unilateral blindness. Seven infants had associated severe or moderate cerebral palsy and sensory disabilities. For some surviving children who were lost to follow-up, } \\
\text { the disability status was unknown, and consequently only multiple imputation analysis was possible. } \\
\text { łAll but one neonate born at 22-23 weeks died. }\end{array}$} \\
\hline
\end{tabular}

of higher socioeconomic status, but fewer mothers were born in France. The proportions of children receiving antenatal steroids and surfactant increased while the proportion of children receiving postnatal steroids decreased. In addition, a lower proportion of children had severe neonatal morbidities in all gestational age groups.

Factors associated with cerebral palsy and ASQ scores below threshold in the EPIPAGE- 2 cohort

We examined factors associated with cerebral palsy and ASQ scores below threshold in children born at 24-31 weeks' gestation (see web appendix 7). Gestational age and small for gestational age were important predictors of cerebral palsy; extremely low gestational age, male sex, small for gestational age, and low parental socioeconomic status increased the risk of an ASQ score below threshold. For those born at 32-34 weeks' gestation, cases of cerebral palsy were insufficient to study factors associated with cerebral palsy; only small for gestational age and low parental socioeconomic status were associated with ASQ scores below threshold (data not shown).

Table 3 | Outcomes for children included in the nine regions participating in EPIPAGE (1997) and EPIPAGE-2 (2011) studies by weeks' gestational age (GA)

\begin{tabular}{|c|c|c|c|c|c|c|c|c|}
\hline \multirow[b]{2}{*}{ Outcomes } & \multicolumn{2}{|l|}{1997} & \multicolumn{2}{|c|}{2011 (EPIPAGE-1 regions) } & \multirow[b]{2}{*}{$\begin{array}{l}\% \text { difference } 2011 v \\
1997^{*}(95 \% \mathrm{Cl})\end{array}$} & \multirow[b]{2}{*}{ Pvalue } & \multirow{2}{*}{$\begin{array}{l}\% \text { adjusted } \\
\text { difference } 2011 v \\
1997^{*}, t(95 \% \mathrm{Cl})\end{array}$} & \multirow[b]{2}{*}{ Pvalue } \\
\hline & $\begin{array}{l}\text { No of events/ } \\
\text { No in group }\end{array}$ & $\%(95 \% \mathrm{Cl})$ & $\begin{array}{l}\text { No of events/ } \\
\text { No in group }\end{array}$ & $\%(95 \% \mathrm{Cl})$ & & & & \\
\hline \multicolumn{9}{|c|}{ Live births } \\
\hline \multicolumn{9}{|c|}{ Survival at 2 years corrected age (weeks' GA)‡: } \\
\hline $22-31$ & $1690 / 2123$ & $79.4(77.5$ to 81.2$)$ & $1520 / 1861$ & $84.1(82.4$ to 85.8$)$ & $4.8(2.6$ to 6.9$)$ & $<0.001$ & $6.0(3.5$ to 8.5$)$ & $<0.001$ \\
\hline $22-23$ & $0 / 46$ & $0.0(\mathrm{NA})$ & $0 / 76$ & $0.0(\mathrm{NA})$ & 0.0 & - & 0.0 & - \\
\hline 24 & $13 / 42$ & $32.7(18.5$ to 49.7$)$ & $28 / 96$ & $29.2(20.3$ to 39.3$)$ & $-3.5(-19.2$ to 12.1$)$ & 0.66 & $-0.6(-17.0$ to 15.8$)$ & 0.94 \\
\hline $25-26$ & $147 / 277$ & $53.2(46.8$ to 59.5$)$ & $231 / 347$ & $66.6(61.3$ to 71.5$)$ & $13.4(6.2$ to 20.6$)$ & $<0.001$ & $12.1(4.9$ to 19.2$)$ & 0.001 \\
\hline $27-31$ & $1530 / 1758$ & 86.8 (85.0 to 88.4$)$ & $1261 / 1342$ & $94.0(92.6$ to 95.2$)$ & $7.2(5.4$ to 9.0$)$ & $<0.001$ & $7.0(5.3$ to 8.8$)$ & $<0.001$ \\
\hline $32-34$ & $1175 / 1211$ & $97.2(95.6$ to 98.3$)$ & $544 / 557$ & 97.7 (96.0 to 98.8) & $0.5(-0.2$ to 1.2$)$ & 0.17 & $0.0(-0.9$ to 0.8$)$ & 0.73 \\
\hline \multicolumn{9}{|c|}{ Survival without neuromotor or sensory disabilities at 2 years corrected age (weeks’ GA)§: } \\
\hline $22-31$ & & $74.5(72.5$ to 76.5$)$ & & 80.5 (78.7 to 82.3) & 6.1 (3.7 to 8.5$)$ & $<0.001$ & $7.2(4.7$ to 9.8$)$ & $<0.001$ \\
\hline $22-23$ & & $0.0(\mathrm{NA})$ & & $0.0(\mathrm{NA})$ & 0.0 & - & 0.0 & - \\
\hline 24 & & $29.0(12.3$ to 45.7$)$ & & $25.8(16.9$ to 34.6$)$ & $-3.2(-20.3$ to 13.8$)$ & 0.71 & $-1.9(-18.9$ to 15.2$)$ & 0.83 \\
\hline $25-26$ & & 45.5 (39.2 to 51.8$)$ & & $62.3(57.1$ to 67.5$)$ & $16.8(3.8$ to 9.4$)$ & $<0.001$ & $17.6(10.2$ to 24.9$)$ & $<0.001$ \\
\hline $27-31$ & & $82.1(80.2$ to 84.1$)$ & & $90.3(88.7$ to 92.0$)$ & $8.2(6.0$ to 10.4$)$ & $<0.001$ & $6.4(1.1$ to 4.4$)$ & $<0.001$ \\
\hline $32-34$ & & 95.7 (94.1 to 97.4$)$ & & 96.8 (95.2 to 98.4$)$ & $1.1(-0.3$ to 2.2$)$ & 0.095 & $0.4(-1.2$ to 2.1$)$ & 0.61 \\
\hline \multicolumn{9}{|c|}{ Survivors at 2 years corrected age $¥$} \\
\hline \multicolumn{9}{|c|}{ Cerebral palsy (weeks' GA): } \\
\hline $24-31$ & $129 / 1415$ & $9.0(7.5$ to 10.6$)$ & $71 / 1280$ & $5.4(4.2$ to 6.8$)$ & $-3.6(-5.3$ to -1.8$)$ & $<0.001$ & $-3.3(-5.0$ to -1.6$)$ & $<0.001$ \\
\hline 24 & $1 / 11$ & 7.1 (0.1 to 38.8$)$ & $4 / 26$ & 15.4 (4.4 to 34.9$)$ & $8.2(-11.1$ to 27.6$)$ & 0.40 & $11.4(-22.0$ to 44.7$)$ & 0.50 \\
\hline $25-26$ & $23 / 133$ & 17.8 (11.4 to 25.9$)$ & 15/191 & 7.9 (4.5 to 12.6$)$ & $-9.9(-16.9$ to -2.9$)$ & 0.005 & $-8.6(-16.5$ to -0.6$)$ & 0.035 \\
\hline $27-31$ & $105 / 1271$ & $8.0(6.6$ to 9.7$)$ & $52 / 1063$ & $4.9(3.7$ to 6.4$)$ & $-3.2(-4.9$ to -1.4$)$ & $<0.001$ & $-2.7(-4.5$ to -0.9$)$ & 0.003 \\
\hline $32-34$ & $30 / 847$ & $2.8(1.5$ to 4.7$)$ & $1 / 416$ & $0.2(0.0$ to 1.3$)$ & $-2.6(-3.2$ to -1.9$)$ & $<0.001$ & $-3.3(-5.9$ to -0.7$)$ & 0.014 \\
\hline \multicolumn{9}{|c|}{$\begin{array}{l}\text { Percentages are weighted to account for differences in sampling process between gestational age groups. } \\
\text { * Risk differences were estimated with a binomial model with identity link. } \\
\text { t Adjusted for gestational age, sex, small for gestational age, and multiple pregnancy. } \\
\text { f Complete cases analysis. No survivors at } 22-23 \text { weeks in the nine regions participating in both EPIPAGE studies. } \\
\text { \& Results based on data using multiple imputation. Severe or moderate neuromotor or sensory disability: severe=cerebral palsy GMFCS levels } 3-5 \text { and/or bilateral deafness and/or bilateral } \\
\text { blindness; moderate=cerebral palsy GMFCS level-2 and/or unilateral deafness and/or unilateral blindness. }\end{array}$} \\
\hline
\end{tabular}




\begin{tabular}{|c|c|c|c|c|c|}
\hline \multirow{2}{*}{\multicolumn{6}{|c|}{$\begin{array}{l}\text { Table } 4 \text { | Comparison of } \\
\text { births included in the ni } \\
\text { cases analysis. Data are } \\
\text { Variables } \\
\text { Maternal characteristics }\end{array}$}} \\
\hline & & & & & \\
\hline \multicolumn{6}{|l|}{ Maternal age (years): } \\
\hline$<25$ & $770 / 3300$ & 22.3 & $456 / 2416$ & 16.3 & $<0.001$ \\
\hline $25-34$ & $2015 / 3300$ & 61.8 & $1446 / 2416$ & 61.0 & \\
\hline$\geq 35$ & $515 / 3300$ & 15.9 & $514 / 2416$ & 22.7 & \\
\hline Birth outside of France & $477 / 2978$ & 17.6 & $655 / 2344$ & 25.4 & $<0.001$ \\
\hline \multicolumn{6}{|c|}{ Parents' socioeconomic statust: } \\
\hline Professional/Intermediate & $1113 / 3065$ & 38.3 & $968 / 2269$ & 44.8 & $<0.001$ \\
\hline Others & $1746 / 3065$ & 54.9 & $1222 / 2269$ & 51.8 & \\
\hline Unknown occupation & $206 / 3065$ & 6.8 & $79 / 2269$ & 3.4 & \\
\hline \multicolumn{6}{|l|}{ Obstetric factors } \\
\hline Multiple pregnancy & $1048 / 3334$ & 31.5 & $815 / 2418$ & 35.7 & 0.020 \\
\hline \multicolumn{6}{|l|}{ Antenatal steroids (weeks' GA): } \\
\hline $22-31$ & $1478 / 2054$ & 73.2 & $1464 / 1833$ & 80.9 & $<0.001$ \\
\hline $22-23$ & $9 / 44$ & 24.1 & $6 / 72$ & 8.3 & 0.024 \\
\hline 24 & $15 / 40$ & 38.0 & $54 / 95$ & 56.8 & 0.056 \\
\hline $25-26$ & $166 / 269$ & 63.7 & $276 / 342$ & 80.7 & $<0.001$ \\
\hline $27-31$ & $1288 / 1701$ & 76.9 & $1128 / 1324$ & 85.2 & $<0.001$ \\
\hline $32-34$ & $836 / 1179$ & 69.0 & $431 / 543$ & 79.4 & $<0.001$ \\
\hline \multicolumn{6}{|l|}{ Caesarean section (weeks' GA): } \\
\hline $22-31$ & $1127 / 2100$ & 52.8 & $1043 / 1846$ & 58.5 & $<0.001$ \\
\hline $22-23$ & $1 / 46$ & 1.8 & $2 / 73$ & 2.7 & 0.71 \\
\hline 24 & $1 / 41$ & 2.0 & $12 / 92$ & 13.0 & 0.027 \\
\hline $25-26$ & $72 / 275$ & 25.9 & $138 / 342$ & 40.4 & $<0.001$ \\
\hline $27-31$ & $1053 / 1738$ & 59.7 & $891 / 1339$ & 66.5 & $<0.001$ \\
\hline $32-34$ & $714 / 1207$ & 53.1 & $278 / 555$ & 50.1 & 0.30 \\
\hline \multicolumn{6}{|l|}{ Neonatal factors } \\
\hline Male & $1789 / 3328$ & 54.0 & $1303 / 2418$ & 53.9 & 0.96 \\
\hline Small for gestational age $\neq$ & $1243 / 3328$ & 36.7 & $799 / 2416$ & 33.3 & 0.061 \\
\hline \multicolumn{6}{|l|}{ Surfactant (weeks’ GA)§: } \\
\hline $22-31$ & $992 / 1967$ & 49.7 & $1116 / 1694$ & 63.9 & $<0.001$ \\
\hline $22-23$ & $5 / 6$ & 83.3 & $3 / 4$ & 75.0 & 0.75 \\
\hline 24 & $23 / 27$ & 82.9 & $52 / 53$ & 98.1 & 0.013 \\
\hline $25-26$ & $181 / 233$ & 78.2 & $319 / 324$ & 98.5 & $<0.001$ \\
\hline $27-31$ & $783 / 1701$ & 45.1 & $742 / 1313$ & 56.5 & $<0.001$ \\
\hline $32-34$ & $168 / 1170$ & 8.5 & $64 / 536$ & 11.9 & 0.037 \\
\hline \multicolumn{6}{|c|}{ Postnatal steroids (weeks' GA)§: } \\
\hline $22-31$ & $459 / 1965$ & 23.6 & $151 / 1656$ & 8.2 & $<0.001$ \\
\hline $22-23$ & $1 / 6$ & 16.7 & $0 / 4$ & 0.0 & \\
\hline 24 & $13 / 27$ & 48.6 & $15 / 51$ & 29.4 & 0.11 \\
\hline $25-26$ & $126 / 232$ & 55.0 & $77 / 319$ & 24.1 & $<0.001$ \\
\hline $27-31$ & $319 / 1700$ & 18.9 & $59 / 1282$ & 4.6 & $<0.001$ \\
\hline $32-34$ & $26 / 1169$ & 1.2 & $1 / 531$ & 0.2 & 0.025 \\
\hline \multicolumn{6}{|c|}{$\begin{array}{l}\text { Severe neonatal morbidities (weeks' } \\
\text { GA)§ף: }\end{array}$} \\
\hline $22-31$ & $693 / 1906$ & 36.1 & $303 / 1602$ & 17.5 & $<0.001$ \\
\hline $22-23$ & $6 / 6$ & 100.0 & $0 / 2$ & 0.0 & \\
\hline 24 & $26 / 27$ & 97.1 & $28 / 47$ & 59.6 & $<0.001$ \\
\hline $25-26$ & $173 / 229$ & 74.4 & $119 / 293$ & 40.6 & $<0.001$ \\
\hline $27-31$ & $488 / 1644$ & 29.4 & $156 / 1260$ & 12.4 & $<0.001$ \\
\hline $32-34$ & $83 / 1123$ & 5.6 & $8 / 515$ & 1.6 & $<0.001$ \\
\hline \multicolumn{6}{|c|}{$\begin{array}{l}\text { Denominators vary according to number of missing data for each variable. Percentages are weighted to account for differences in sampling process } \\
\text { between gestational age groups. } \\
\text { *Comparison between } 1997 \text { and } 2011 \text {. } \\
\text { tDefined as highest occupational status of mother and father, or mother only if living alone. } \\
\text { FSmall for gestational age was defined as birth weight less than the } 10 \text { th centile for gestational age and sex based on French intrauterine "EPOPé" } \\
\text { growth curves (Ego et al } 2016^{33} \text { ). } \\
\text { \$Related to infants admitted to neonatal intensive care units. } \\
\text { ISevere neonatal morbidity was defined as severe bronchopulmonary dysplasia or necrotising enterocolitis stage } 2-3 \text { or severe retinopathy of } \\
\text { prematurity stage }>3 \text { or any of the following severe cerebral abnormalities on cranial ultrasonography: intraventricular haemorrhage grade III or IV or } \\
\text { cystic periventricular leukomalacia (Ancel et al } 2015^{2} \text { ). }\end{array}$} \\
\hline
\end{tabular}

Discussion

In this French population based cohort of neonates born at 22-34 weeks' gestation in 2011, rates of survival without severe or moderate neuromotor and sensory disabilities at 2 years corrected age of $48.5 \%, 90.0 \%$, and $97.5 \%$ were observed for children born at 22-26, 27-31, and 32-34 weeks' gestation, respectively. Only one child born at 22- 
23 weeks' gestation survived. After adjustment for changes in the baseline characteristics of infants over time, rates of survival and survival without severe or moderate neuromotor and sensory disabilities at 2 years corrected age increased between 1997 and 2011 for children born at 22-31 weeks' gestation but no change was found for children born at 24 weeks' gestation or earlier. Rates of cerebral palsy decreased by $3.3 \%$ between the two epochs, which was statistically significant, at both 24-31 and 32-34 weeks' gestation. After excluding children with cerebral palsy, blindness, deafness, or severe congenital brain malformations, 50.2\%, 40.7\%, and $36.2 \%$ of children born at 24-26, 27-31, and 32-34 weeks' gestation, respectively, had Ages and Stages Questionnaire (ASQ) scores below threshold and were considered at risk of developmental delay. Communication and personal-social domains were the domains most frequently scoring below threshold.

\section{Strengths and limitations of this study}

The strengths of the EPIPAGE-2 study include the population based cohort design, at a national level, with prospective enrolment of a large number of infants born not only extremely preterm but also very and moderately preterm, whose outcome has been infrequently reported. We used standardised definitions of outcomes following international recommendations, ${ }^{21}$ thus allowing comparison with other international cohorts. In addition, we obtained face to face assessments to diagnose cerebral palsy and we explored the full range of development with the ASQ to better understand profiles of development by gestational age group.

The main limitation of the study was the number of children lost to follow-up, although the follow-up rate was high in terms of the size of the cohort. Results from other studies ${ }^{36}$ suggest an excess of poorly performing children among those not evaluated because the parents of children from more disadvantaged families are more often non-responders. We also found a social bias in participation, with more families of a low socioeconomic status initially refusing participation or not responding at two years. We used multiple imputation to account for missing data. This did not modify the rate of cerebral palsy but showed a consistent increase across gestational age groups in the proportion of children with ASQ scores below threshold, similar to the impact of socioeconomic status on development seen in other studies. ${ }^{5}$ In addition, because of the number of doctors involved in the study, their ability to diagnose cerebral palsy might have varied. However, this was a pragmatic choice that means our results also reflect how cerebral palsy is diagnosed in routine practice. Milder forms of cerebral palsy may have been missed but most of the doctors were paediatricians involved in the routine follow-up of children born preterm, and a standardised questionnaire was used to minimise ambiguous answers. Finally, the lack of cognitive evaluation by trained psychologists may limit comparisons with other cohorts. We used the ASQ, a parent based developmental questionnaire, reported as useful to identify children at risk of having a developmental quotient less than $85,{ }^{37}$ with a sensitivity of $87 \%$ and a specificity of $77 \% .{ }^{24}$ However, the correlation between the ASQ score and a standardised, professionally administered developmental test score is higher in preterm children than term born children, ${ }^{38}$ increases with increasing age at assessment, ${ }^{38}$ and two years seems a reliable period to assess neurodevelopment with the ASQ. ${ }^{26}$ 39-41 In addition, children born preterm with low scores on the ASQ at 2 years of age, but without neurodevelopmental impairment, have statistically lower Bayley Scales of Infant Development scores compared with children with ASQ scores above threshold, ${ }^{40}$ and, more recently, the predictive value of ASQ at 3 years for IQ at 5-6 years has been described. ${ }^{42}$ Nevertheless, assessing neurodevelopment at 2 years, compared with later school age outcomes, is challenging as a child's development does not have a fixed trajectory and some children will recover from developmental delay while for others their deficit will become apparent as they grow. ${ }^{43} 44$ Children identified early using parental questionnaires might benefit from closer follow-up and a standardised evaluation with formal psychometric tests. Our data offer real life estimates, at a national level, of the number of children in each gestational age grouping who may need to be included in formal follow-up using parental questionnaires to assess development. As expected, parents who did not complete the questionnaire or completed the questionnaire outside the expected age range were of a lower socioeconomic status, and thus may need additional support when assessing development with a parental questionnaire. The decline in the rates of cerebral palsy that we observed is consistent with those of cerebral palsy registers describing a decreased prevalence of cerebral palsy over time, and a substantial reduction in the most severe forms, especially in very low and moderately low birthweight neonates. ${ }^{45-47}$ As for other cohorts based on gestational age, ${ }^{5}$ we did not find a reduction in the most severe forms (data not shown), but the number of children with severe cerebral palsy was too small to observe such a difference. Rates of sensory impairments were very low but reporting sensory outcomes at extremely low gestation is essential because impairment increases with age. In the EXPRESS cohort, the frequencies of blindness and visual impairment increased between 30 months' corrected age $^{6}$ and 6.5 years, ${ }^{48}$ with children born before 25 weeks' gestation showing the highest risk of visual problems.

\section{Comparison with other studies}

The improvements in survival and neurodevelopmental outcomes that we observed may reflect advances in implementation of evidence based practices in obstetric and neonatal care. We observed an increase in the use of antenatal corticosteroids and surfactant, together with a decline in the postnatal 
use of steroids, associated with a decrease in severe neonatal morbidities. Our results provide additional evidence for the effectiveness of strategies adopted in the perinatal period, although the respective role of each strategy is unknown. ${ }^{49}$ However, in France, compared with countries with active resuscitation for periviable neonates, ${ }^{561550}$ only one infant born at 2223 weeks' gestation survived, and rates of survival and survival without neuromotor or sensory disabilities were poor for children born at 24 weeks' gestation, with no noticeable improvement between 1997 and 2011 in either practices or outcomes. As expected from the French recommendations, ${ }^{51}{ }^{52}$ we have previously reported that intensive care was withheld or withdrawn in the delivery room for $92.6 \%$ of neonates born at 22 23 weeks' gestation, ${ }^{53}$ with provision of comfort care until death for those born alive. ${ }^{54}$ In The Netherlands, where perinatal care at extremely low gestation is comparable to that in France, the proportion of children with severe or moderate disabilities at 2 years was higher than those we report from France but included children with cognitive impairments. ${ }^{17}$ The impact of active treatment at 22-23 weeks' gestation on outcomes at 24 weeks' gestation and thereafter is a real question. One hypothesis is that if you provide active care at 22-23 weeks' gestation, outcomes at 24-26 weeks' gestation improve. Marked differences in hospital practices regarding the initiation of active treatment in infants born at 22, 23, or 24 weeks' gestation were observed in a sample of units in the USA, with hospital rates of active treatment accounting for nearly 80\% of the between-hospital variation in survival without severe impairment among children born at 22 or 23 weeks, but this relation was attenuated among those born at 24 weeks. ${ }^{55}$ In another paper, the same group suggested that centres with higher rates of antenatal corticosteroids at 22-24 weeks had reduced rates of death and neurodevelopmental impairment among children born at higher gestational age. ${ }^{56}$ We report a $6.9 \%$ rate of cerebral palsy at 24-26 weeks' gestation, with similar proportions at 24 and 25 weeks' gestation and a statistically significant decrease at 26 weeks' gestation. Comparisons with other cohorts are difficult as rates were reported for 22-26 weeks' gestation and not by individual weeks of gestation. Reported rates of cerebral palsy in surviving infants born at 22-26 weeks' gestation vary from $7 \%$ in Sweden ${ }^{6}$ to $10 \%$ in Australia ${ }^{8}$ and $14 \%$ in England. ${ }^{5}$ Further research is needed to better understand the role of different strategies of care on outcomes of extremely premature neonates ${ }^{57}$ and the influence of key practices for periviable births that might improve outcomes in more mature neonates. ${ }^{56}$

The proportion of children with ASQ scores below threshold may appear high in our cohort. On the basis of ASQ reference values, ${ }^{24} 12 \%$ to $17 \%$ of children from the general population are considered to need further evaluation in at least one developmental domain at 2 years. ${ }^{2458}$ Higher proportions have been found at the same age in children born preterm: $41 \%$ of those born before 28 weeks' gestation in a Dutch hospital based cohort $^{40}$ and $46 \%$ in a French regional based cohort of children born at less than 32 weeks' gestation. ${ }^{26}$ As a screening instrument, ASQ identifies more children at risk of developmental delay than those with a diagnosis based on professionally administered psychometric tests. ${ }^{40}$ The risk of potential overidentification has been widely debated, but children with suspected delay may represent a group at risk for future academic difficulties and who could require dedicated support systems. ${ }^{59}$ In each gestational age group, communication was the domain most frequently scoring below threshold, with proportions that were still $17.8 \%$ at 32-34 weeks' gestation. Delay in language development, together with poorer socialemotional competence, was also recently described in an Australian cohort of children born between 32 and 36 weeks, ${ }^{60}$ and stability of poor language performance from 20 months to 8 years of age has been shown to be greater for preterm children than for term children. ${ }^{61}$ Given the high prevalence of births after 31 weeks' gestation, early identification of children at risk of later difficulties to provide targeted interventions may have a broad impact on learning disabilities. We have shown that parents' socioeconomic status and small for gestational age were the main factors associated with ASQ scores below threshold, and these should be considered when planning followup. Few interventions have been shown to have a long term impact on cognitive outcome, but the impact on parents' wellbeing merits consideration. ${ }^{2262}$ Compared with children born at 27-31 or 32-34 weeks' gestation, a higher proportion of children born at 24-26 weeks' gestation showed ASQ scores below threshold in the gross motor domain. Most children failed the most complex gross motor items: "jump with both feet" ("not yet" $=93 \%$ ) and "kicking a ball" ("not yet" or "sometimes" $=78 \%$ ) (data not shown). It is likely that some of these children will be identified later as children with developmental coordination disorders. ${ }^{31}$

\section{Context of the study}

This study evaluated outcomes at 2 years corrected age in a large group of preterm babies, born at 22-34 weeks' gestation. French practices do not differ greatly from those in many other European countries, and our results may be applicable elsewhere. ${ }^{57}$ The proportion of infants at risk of developmental delay was high, even for those born at 32-34 weeks' gestation, which raises the question of including these children in follow-up. This might have a great implication in terms of cost and the size of the workforce required, but individualising follow-up according to risk factors other than gestational age, together with the use of tools easily used in community services, should be considered. Parental questionnaires are increasingly popular: they can be used at the community level to identify children needing further assessment, and decrease the cost of medical expenditure. Further follow-up of our study sample is in progress and will enable us to examine whether ASQ scores below threshold are predictors of later difficulties at 5 years. 
The EPIPAGE-2 cohort study provides an extensive description of practices around birth at extremely low gestation, ${ }^{25354}$ in a country where active perinatal intervention is not currently recommended. ${ }^{5152}$ For infants born at extremely low gestation, a consistent concern in the literature is that increased survival may come at the expense of increased long term sequelae, ${ }^{63}$ although recent studies counter this notion. ${ }^{5615}$ A 2010 European survey exploring national guidelines of resuscitation for infants born at 22-25 weeks' gestation found little consensus on how care is managed. ${ }^{64}$ As in seven other European countries, France favoured non-intervention for infants born before 24 weeks' gestation, ${ }^{64}$ with provision of comfort care until death for those born alive. ${ }^{54}$ Our results invite questioning perinatal strategies in France, and in countries with similar recommendations. However, improving outcomes at extremely low gestational age requires a complex change in philosophy of care and close cooperation not only between obstetricians and neonatologists, but also developmental specialists, parent associations, and policy makers. Efficient regionalised referral systems and antenatal steroids are usually the main focus of intervention advocated to improve outcome, ${ }^{65}$ but countries reporting better outcomes also differ in quality of family centred care and the organisation of follow-up. ${ }^{67}$

\section{Conclusion}

In this national population based cohort of preterm neonates, we showed improvements in survival at 2 years without neuromotor disabilities in each gestational age group between 1997 and 2011. There was a statistically important decrease in the rate of cerebral palsy but the risk of developmental delay was high, even in children born moderately preterm. Parental questionnaires may represent a promising alternative for early identification of children at risk of later difficulties.

\section{AUTHOR AFFILIATIONS}

${ }^{1}$ Obstetrical, Perinatal, and Pediatric Epidemiology Team, Epidemiology and Biostatistics Sorbonne Paris Cité Research Center (U1153), INSERM, Paris, France; Paris Descartes University, Paris, France

${ }^{2} \mathrm{CHU}$ Lille, Department of Neonatal Medicine, Jeanne de Flandre Hospital, F-59000 Lille, France

${ }^{3}$ INSERM UMR 1027, Université Toulouse III Paul Sabatier, Toulouse, France

${ }^{4}$ Biostatistics and Medical Information Department, AP-HP SaintLouis Hospital, Paris, France

5École des Hautes Études en Santé Publique (EHESP), Rennes, France

${ }^{6}$ Maternité Port-Royal, Université Paris Descartes, Groupe Hospitalier Cochin Broca Hôtel-Dieu, Assistance Publique-Hôpitaux de Paris, DHU Risques et Grossesse, Paris, France

${ }^{7}$ Department of Neonatal Pediatrics, Intensive care, and Neuropediatrics, Rouen University Hospital, Rouen, France

${ }^{8}$ Research Unit U1245, Institute for Research and Innovation in Biomedicine, Rouen, France

${ }^{9}$ Clinical Research Unit, Center for Clinical Investigation P1419, Cochin Broca Hôtel-Dieu Hospital, Paris, France

EPIPAGE-2 writing group: D Astruc, P Kuhn, J Matis, L Joly, G Mazeira, A David, B Lecomte, F Vendittelli, V Datin-Dorriere, B Guillois, A Burguet, P Sagot, JM Roué, A Beuchée, F Rouget, E Saliba, A Favreau, N Bednarek, G Loron, C Mougey, G Thiriez, S Marret, C Lardennois, H Bruel, X Durrmeyer, M Granier, P Boileau, G Kayem, R Carbajal, A
Lapillonne, PH Jarreau, G Cambonie, I Souksi-Médioni, AC Menguy, A Bédu, F Mons, V Valdes, J Fresson, C Alberge, C Arnaud, O Dicky, P Truffert, A Mitha, ML Charkaluk, C Gire, F Boubred, C D’Ercole, A Bongain, JC Rozé, C Flamant, G Gascoin, A Leke, S Goudjil, M Debeir, O Claris, JC Picaud, T Debillon, H Patural, A Poulichet, A Abrial, A Favre, S Buende, O Fléchelles, D Ramful, PY Robillard, V Benhammou, L FoixL'Hélias (see web appendix 9).

EPIPAGE-2 study group: D Astruc, P Kuhn, B Langer, J Matis, C Ramousset, X Hernandorena, P Chabanier, L Joly-Pedespan, MJ Costedoat, A Leguen, B Lecomte, D Lemery, F Vendittelli, G Beucher, M Dreyfus, B Guillois, Y Toure, A Burguet, S Couvreur, JB Gouyon, P Sagot, N Colas, I Sizun, A Beuchée, P Pladys, F Rouget, RP Dupuy, D Soupre, F Charlot, S Roudaut, A Favreau, E Saliba, L Reboul, N Bednarek, P Morville, V Verrière, G Thiriez, C Balamou, L Marpeau, S Marret, C Barbier, G Kayem, X Durrmeyer, M Granier, M Ayoubi, A Baud, B Carbonne, L Foix L'Hélias, F Goffinet, PH Jarreau, D Mitanchez, P Boileau, L Cornu, R Moras, P Boulot, G Cambonie, H Daudé, A Badessi, N Tsaoussis, A Bédu, F Mons, C Bahans, MH Binet, J Fresson, JM Hascoët, A Milton, O Morel, R Vieux, L Hilpert, C Alberge, C Arnaud, C Vayssière, M Baron, ML Charkaluk, V Pierrat, D Subtil, P Truffert, S Akowanou, D Roche, C D’Ercole, C Gire, U Simeoni, A Bongain, M Deschamps, B Branger, JC Rozé, N Winer, V Rouger, C Dupont, J Gondry, G Krim, B Baby, M Debeir, O Claris, JC Picaud, S Rubio-Gurung, C Cans, A Ego, T Debillon, H Patural, A Rannaud, E Janky, A Poulichet, IM Rosenthal, E Coliné, A Favre, N Joly, S Châlons, V Lochelongue, PY Robillard, S Samperiz, D Ramful, PY Ancel, V Benhammou, B Blondel, M Bonet, A Brinis, ML Charkaluk, A Coquelin, C Duffaut, M Durox, L Foix-L'Hélias, F Goffinet, M Kaminski, G Kayem, B Khoshnood, C Lebeaux, E Lorthe, L Marchand-Martin, AS Morgan, V Pierrat, J Rousseau, MJ Saurel-Cubizolles, D Sylla, D Tran, LVasante-Annamale, J Zeitlin (see web appendix 9)

We are grateful for the participation of all families of preterm infants in the EPIPAGE-2 cohort study and for the cooperation of all maternity and neonatal units in France. We thank parents' associations (SOS Prema, Collectif Interassociatif Autour de la NaissancE (CIANE), Jumeaux et Plus, Soins Palliatifs et Accompagnement en MAternité (SPAMA)) for their overwhelming support and their involvement in the dissemination of the results. We thank the EPIPAGE-2 study group for its substantial contribution to the conception, design, and acquisition of data

Contributors: VP, LMM, and PYA had full access to all the data in the study and take responsibility for the integrity of the data and the accuracy of the data analysis. VP, CA, MK, ASM, FBL, and SM conceptualised the study and wrote the manuscript. LMM and MRR performed the statistical analysis. CL coordinated data collection and had responsibility for technical support. PYA obtained funding and supervised the study. All authors contributed to the analysis plan and interpretation of the results, and reviewed and approved the final manuscript. All members of the writing group were involved in the regional organisation for data collection, reviewed, and approved the final manuscript. VP is the guarantor.

Funding: This project has been funded with support from the following organisations: The French Institute of Public Health Research/Institute of Public Health and its partners: the French Health Ministry, the National Institute of Health and Medical Research (INSERM), the National Institute of Cancer, and the National Solidarity Fund for Autonomy (CNSA); The National Research Agency through the French EQUIPEX program of investments in the future (reference ANR-11-EQPX-0038); the PREMUP Foundation; Fondation de France (reference 00050329); and Fondation pour la Recherche Médicale (reference SPF20160936356). The funders had no role in the study design, data collection and analysis, decision to publish, or preparation of the manuscript.

Competing interests: All authors have completed the ICMJE uniform disclosure form at www.icmje.org/coi_disclosure.pdf and declare: no support from any organisation for the submitted work; no financial relationships with any organisations that might have an interest in the submitted work in the previous three years; no othe relationships or activities that could appear to have influenced the submitted work

Ethical approval: This study was approved by the National Data Protection Authority (CNIL no.911009) and by appropriate ethics committees (Consultative Committee on the Treatment of Data on Personal Health for Research Purposes - reference no. 10.626, Committee for the Protection of People Participating in Biomedical Research - reference CPP SC-2873)

Data sharing: The EPIPAGE studies are subject to a data sharing policy that may be downloaded from http://epipage2.inserm.fr/index. php/en/. 
Transparency: The manuscript's guarantor (VP) affirms that the manuscript is honest, accurate and transparent account of the study being reported; that no important aspects of the study have been omitted; and that any discrepancies from the study as planned have been explained.

This is an Open Access article distributed in accordance with the Creative Commons Attribution Non Commercial (CC BY-NC 4.0) license, which permits others to distribute, remix, adapt, build upon this work non-commercially, and license their derivative works on different terms, provided the original work is properly cited and the use is noncommercial. See: http://creativecommons.org/licenses/by-nc/4.0/.

1 Costeloe KL, Hennessy EM, Haider S, Stacey F, Marlow N, Draper ES. Short term outcomes after extreme preterm birth in England: comparison of two birth cohorts in 1995 and 2006 (the EPICure studies). BMJ 2012;345:e7976. doi:10.1136/bmj.e7976.

2 Ancel PY, Goffinet F Kuhn P et al. EPIPAGE-2 Writing Group. Survival and morbidity of preterm children born at 22 through 34 weeks' gestation in France in 2011: results of the EPIPAGE-2 cohort study. JAMA Pediatr 2015;169:230-8. doi:10.1001/ jamapediatrics.2014.3351.

3 Fellman V, Hellström-Westas L, Norman M, et al. EXPRESS Group. One-year survival of extremely preterm infants after active perinatal care in Sweden. JAMA 2009;301:2225-33. doi:10.1001/jama.2009. 771.

4 Stoll BJ, Hansen NI, Bell EF, et al. Eunice Kennedy Shriver National Institute of Child Health and Human Development Neonatal Research Network. Trends in Care Practices, Morbidity, and Mortality of Extremely Preterm Neonates, 1993-2012. JAMA 2015;314:103951. doi:10.1001/jama.2015.10244.

5 Moore T, Hennessy EM, Myles J, et al. Neurological and developmental outcome in extremely preterm children born in England in 1995 and 2006: the EPICure studies. BM/ 2012;345:e7961. doi:10.1136/bmj.e7961

6 Serenius F, Källén K, Blennow M, et al. EXPRESS Group. Neurodevelopmental outcome in extremely preterm infants at 2.5 years after active perinatal care in Sweden. JAMA 2013;309:181020. doi:10.1001/jama.2013.3786

7 Serenius F, Ewald U, Faroogi A, et al. Extremely Preterm Infants in Sweden Study Group. Neurodevelopmental outcomes among extremely preterm infants 6.5 Years after active perinatal care in Sweden. JAMA Pediatr 2016;170:954-63. doi:10.1001/ jamapediatrics.2016.1210.

8 Doyle LW, Roberts G, Anderson PJ. Victorian Infant Collaborative Study Group. Outcomes at age 2 years of infants < 28 weeks' gestational age born in Victoria in 2005. J Pediatr 2010;156:49-53.e1. doi:10.1016/i.jpeds.2009.07.013.

9 Johnson S, Evans TA, Draper ES, et al. Neurodevelopmental outcomes following late and moderate prematurity: a population-based cohort study. Arch Dis Child Fetal Neonatal Ed 2015;100:F301-8. doi:10.1136/archdischild-2014-307684.

10 Quigley MA, Poulsen G, Boyle E, et al. Early term and late preterm birth are associated with poorer school performance at age 5 years: a cohort study. Arch Dis Child Fetal Neonatal Ed 2012;97:F167-73. doi:10.1136/archdischild-2011-300888.

11 Doyle LW, Anderson PJ. Adult outcome of extremely preterm infants. Pediatrics 2010;126:342-51. doi:10.1542/peds.2010-0710.

12 Saigal S, Day KL, Van Lieshout RJ, Schmidt LA, Morrison KM, Boyle MH. Health, wealth, social integration, and sexuality of extremely low-birth-weight prematurely born adults in the fourth decade of life. JAMA Pediatr 2016;170:678-86. doi:10.1001/ jamapediatrics.2016.0289

13 Vanhaesebrouck P, Allegaert K, Bottu J, et al. Extremely Preterm Infants in Belgium Study Group. The EPIBEL study: outcomes to discharge from hospital for extremely preterm infants in Belgium. Pediatrics 2004;114:663-75. doi:10.1542/peds.2003-0903-L.

14 Stoll BJ, Hansen NI, Bell EF, et al. Eunice Kennedy Shriver National Institute of Child Health and Human Development Neonatal Research Network. Neonatal outcomes of extremely preterm infants from the NICHD Neonatal Research Network. Pediatrics 2010;126:443-56. doi:10.1542/peds.2009-2959.

15 Younge N, Goldstein RF, Bann CM, et al. Eunice Kennedy Shriver National Institute of Child Health and Human Development Neonatal Research Network. Survival and Neurodevelopmental Outcomes among Periviable Infants. N Engl / Med 2017;376:617-28. doi:10.1056/NEJMoa1605566

16 Guillén Ú, Weiss EM, Munson D, et al. Guidelines for the Management of Extremely Premature Deliveries: A Systematic Review. Pediatrics 2015;136:343-50. doi:10.1542/peds.2015-0542.

17 de Waal CG, Weisglas-Kuperus N, van Goudoever JB, Walther FI. NeoNed Study Group, LNF Study Group. Mortality, neonatal morbidity and two year follow-up of extremely preterm infants born in The Netherlands in 2007. PLoS One 2012;7:e41302. doi:10.1371/ journal.pone.0041302.
18 Larroque B, Ancel PY, Marret S, et al. EPIPAGE Study group. Neurodevelopmental disabilities and special care of 5-yearold children born before 33 weeks of gestation (the EPIPAGE study): a longitudinal cohort study. Lancet 2008;371:813-20. doi:10.1016/S0140-6736(08)60380-3

19 Larroque B, Ancel PY, Marchand-Martin L, et al. Epipage Study group. Special care and school difficulties in 8-year-old very preterm children: the Epipage cohort study. PLoS One 2011;6:e21361. doi:10.1371/journal.pone.0021361.

20 Spittle A, Orton J, Anderson PJ, Boyd R, Doyle LW. Early developmental intervention programmes provided post hospital discharge to prevent motor and cognitive impairment in preterm infants. In: The Cochrane Collaboration, ed. Cochrane Database of Systematic Reviews. Chichester, UK: John Wiley \& Sons, Ltd; 2015. http:// doi.wiley.com/10.1002/14651858.CD005495.pub4. Accessed December 29, 2016

21 Rysavy MA, Marlow N, Doyle LW, et al. Reporting Outcomes of extremely preterm births. Pediatrics 2016. Sep;138(3): pii: 20160689. doi:10.1542/peds.2016-0689.

22 van Wassenaer-Leemhuis AG, Jeukens-Visser M, van Hus JWP, et al. Rethinking preventive post-discharge intervention programmes for very preterm infants and their parents. Dev Med Child Neurol 2016;58(Suppl 4):67-73. doi:10.1111/dmcn.13049.

23 Blaggan S, Guy A, Boyle EM, et al. A parent questionnaire for developmental screening in infants born late and moderately preterm. Pediatrics 2014;134:e55-62. doi:10.1542/peds.20140266.

24 Squire J, Twombly E, Bricker D, Potter L. ASQ-3:User’s guide. BaltimoreBrookes Publishing: Ages \& Stages Questionnaires $®$, Third Edition (ASQ-3 ${ }^{\text {TM}}$ ), 2009. http://products.brookespublishing. com/Ages-Stages-Questionnaires-Third-Edition-ASQ-3-P569.aspx. Accessed December 28, 2016.

25 Council on Children With Disabilities. Section on Developmental Behavioral Pediatrics. Bright Futures Steering Committee. Medical Home Initiatives for Children With Special Needs Project Advisory Committee. Identifying infants and young children with developmental disorders in the medical home: an algorithm for developmental surveillance and screening Pediatrics 2006;118:405-20. doi:10.1542/peds.2006-1231

26 Flamant C, Branger B, Nguyen The Tich S, et al. Parent-completed developmental screening in premature children: a valid tool for follow-up programs. PLoS One 2011;6:e20004. doi:10.1371/ journal.pone.0020004.

27 Janson H, Squires J. Parent-completed developmental screening in Norwegian population sample: a comparison with US normative data. Acta Paediatr 2004;93:1525-9. doi:10.1111/j.1651-2227.2004. tb02641.x.

28 Ancel PY, Goffinet F. EPIPAGE 2 Writing Group. EPIPAGE 2: a preterm birth cohort in France in 2011. BMC Pediatr 2014;14:97. doi:10.1186/1471-2431-14-97.

29 Larroque B. [EPIPAGE: epidemiologic study of very premature infants. Protocol of the survey]. Arch Pediatr 2000;7(Suppl 2):339s-42s. doi:10.1016/S0929-693X(00)80094-9

30 Surveillance of Cerebral Palsy in Europe. Surveillance of cerebral palsy in Europe: a collaboration of cerebral palsy surveys and registers. Dev Med Child Neurol 2000;42:816-24

31 Ghassabian A, Sundaram R, Bell E, Bello SC, Kus C, Yeung E. Gross Motor milestones and subsequent development. Pediatrics 2016;138:e20154372-20154372. doi:10.1542/ peds.2015-4372.

32 Classification of health status at 2 years as a perinatal outcome. Report of a BAPM/RCPCH Working group. http://www.bapm.org/ publications/documents/guidelines/Outcome_BAPM_WG_report_ v6 Jan08.pdf. Accessed December 28, 2016.

33 Ego A, Prunet C, Lebreton E, et al. [Customized and non-customized French intrauterine growth curves. I - Methodology]. J Gynecol Obstet Biol Reprod (Paris) 2016;45:155-64. doi:10.1016/j. jgyn.2015.08.009.

34 White IR, Royston P, Wood AM. Multiple imputation using chained equations: Issues and guidance for practice. Stat Med 2011;30: 377-99. doi:10.1002/sim.4067.

35 Rubin DB. Frontmatter. In: Multiple Imputation for Nonresponse in Surveys. John Wiley \& Sons, Inc, 1987: i-xxix, doi:10.1002/9780470316696.fmatter.

36 Wolke D, Söhne B, Ohrt B, Riegel K. Follow-up of preterm children: important to document dropouts. Lancet 1995;345:447. doi:10.1016/S0140-6736(95)90425-5

37 Velikonja T, Edbrooke-Childs J, Calderon A, Sleed M, Brown A, Deighton J. The psychometric properties of the Ages \& Stages Questionnaires for ages 2-2.5: a systematic review. Child Care Health Dev 2017;43:1-17. doi:10.1111/cch.12397.

38 Schonhaut L, Armijo I, Schönstedt M, Alvarez j, Cordero M. Validity of the ages and stages questionnaires in term and preterm infants. Pediatrics 2013;131:e1468-74. doi:10.1542/peds.2012-3313. 
39 Steenis LJP, Verhoeven M, Hessen DJ, van Baar AL. Parental and professional assessment of early child development: the ASQ-3 and the Bayley-III-NL. Early Hum Dev 2015;91:217-25. doi:10.1016/j. earlhumdev.2015.01.008

40 Kerstjens JM, Nijhuis A, Hulzebos CV, et al. The Ages and Stages Questionnaire and neurodevelopmental Impairment in two-year-old preterm-born children. PLoS One 2015;10:e0133087. doi:10.1371/ journal.pone.0133087.

41 Agarwal PK, Shi L, Daniel LM, et al. Prospective evaluation of the Ages and Stages Questionnaire 3rd Edition in very-low-birthweight infants. Dev Med Child Neurol. 2017;59:484-489. doi:10.1111/ dmcn.13307.

42 Charkaluk M-L, Rousseau J, Calderon J, et al. EDEN Mother-Child Cohort Study Group. Ages and Stages Questionnaire at 3 Years for Predicting IQ at 5-6 Years. Pediatrics 2017;139:e20162798. doi:10.1542/peds.2016-2798

43 Marlow N, Wolke D, Bracewell MA, Samara M. EPICure Study Group. Neurologic and developmental disability at six years of age after extremely preterm birth. N Engl J Med 2005;352:9-19. doi:10.1056/ NEJMoa041367.

44 Schmidt B, Anderson PJ, Doyle LW, et al. Caffeine for Apnea of Prematurity (CAP) Trial Investigators. Survival without disability to age 5 years after neonatal caffeine therapy for apnea of prematurity. JAMA 2012;307:275-82. doi:10.1001/jama.2011.2024.

45 Sellier E, Platt MJ, Andersen GL, Krägeloh-Mann I, De La Cruz J, Cans C. Surveillance of Cerebral Palsy Network. Decreasing prevalence in cerebral palsy: a multi-site European population-based study, 1980 to 2003. Dev Med Child Neurol 2016;58:85-92. doi:10.1111/ dmcn.12865.

46 Reid SM, Dagia CD, Ditchfield MR, Carlin JB, Reddihough DS Population-based studies of brain imaging patterns in cerebral palsy. Dev Med Child Neurol 2014:56:222-32. doi:10.1111/dmcn.12228.

47 Himmelmann K, Sundh V. Survival with cerebral palsy over five decades in western Sweden. Dev Med Child Neurol 2015;57:762-7. doi:10.1111/dmcn.12718.

48 Hellgren KM, Tornqvist K, Jakobsson PG, et al. Ophthalmologic Outcome of Extremely Preterm Infants at 6.5 Years of Age: Extremely Preterm Infants in Sweden Study (EXPRESS). JAMA Ophthalmol 2016;24:Mar 24. doi:10.1001/ jamaophthalmol.2016.0391.

49 Reid SM, Meehan E, McIntyre S, Goldsmith S, Badawi N, Reddihough DS. Australian Cerebral Palsy Register Group. Temporal trends in cerebral palsy by impairment severity and birth gestation. Dev Med Child Neurol 2016;58(Suppl 2):25-35. doi:10.1111/ dmcn.13001.

50 Schlapbach L), Adams M, Proietti E, et al. Swiss Neonatal Network \& Follow-up Group. Outcome at two years of age in a Swiss nationa cohort of extremely preterm infants born between 2000 and 2008. BMC Pediatr 2012;12:198. doi:10.1186/1471-2431-12-198.

51 Moriette G, Rameix S, Azria E, et al. Groupe de réflexion sur les aspects éthiques de la périnatologie. [Very premature births: Dilemmas and management. Part 1. Outcome of infants born before 28 weeks of postmenstrual age, and definition of a gray zone]. Arch Pediatr 2010;17:518-26. doi:10.1016/j.arcped.2009.09.025.

52 Moriette G, Rameix S, Azria E, et al. Groupe de réflexion sur les aspects éthiques de la périnatologie. [Very premature births: Dilemmas and management. Second part: Ethical aspects and recommendations]. Arch Pediatr 2010;17:527-39. doi:10.1016/j. arcped.2009.09.024.

53 Perlbarg J, Ancel PY, Khoshnood B, et al. Epipage-2 Ethics group. Delivery room management of extremely preterm infants: the EPIPAGE-2 study. Arch Dis Child Fetal Neonatal Ed 2016;101:F38490. doi:10.1136/archdischild-2015-308728.

54 Durrmeyer X, Scholer-Lascourrèges C, Boujenah L, et al. EPIPAGE-2 Extreme Prematurity Writing Group. Delivery room deaths of extremely preterm babies: an observational study. Arch Dis Child Fetal Neonatal Ed 2017;102:F98-103. doi:10.1136/archdischild-2016-310718.

55 Rysavy MA, Li L, Bell EF, et al. Eunice Kennedy Shriver National Institute of Child Health and Human Development Neonatal Research Network. Between-hospital variation in treatment and outcomes in extremely preterm infants. N Engl J Med 2015;372:1801-11. doi:10.1056/NEJMoa1410689.

56 Smith PB, Ambalavanan N, Li L, et al. Generic Database Subcommittee. Kennedy Shriver National Institute of Child Health Human Development Neonatal Research Network. Approach to infants born at 22 to 24 weeks' gestation: relationship to outcomes of more-mature infants. Pediatrics 2012;129:e1508-16. doi:10.1542/peds.2011-2216.

57 Zeitlin J, Manktelow BN, Piedvache A, et al. EPICE Research Group. Use of evidence based practices to improve survival without severe morbidity for very preterm infants: results from the EPICE population based cohort. BMJ 2016;354:i2976. doi:10.1136/bmj.i2976.

58 Veldhuizen S, Clinton J, Rodriguez C, Wade TJ, Cairney J. Concurrent validity of the Ages And Stages Questionnaires and Bayley Developmental Scales in a general population sample. Acad Pediatr 2015:15:231-7 doi:10.1016/j.acap.2014.08.002.

59 Glascoe FP. Are overreferrals on developmental screening tests really a problem?Arch Pediatr Adolesc Med 2001;155:54-9. doi:10.1001/ archpedi.155.1.54

60 Cheong JL, Doyle LW, Burnett AC, et al. Association between moderate and late preterm birth and neurodevelopment and social-emotional development at age 2 Years. JAMA Pediatr 2017;171:e164805. doi:10.1001/jamapediatrics.2016.4805.

61 Putnick DL, Bornstein MH, Eryigit-Madzwamuse S, Wolke D. LongTerm stability of language performance in very preterm, moderatelate preterm, and term children. J Pediatr 2017;181:74-79.e3. doi:10.1016/j.jpeds.2016.09.006.

62 Spittle AJ, Barton S, Treyvaud K, Molloy CS, Doyle LW, Anderson PJ. School-Age outcomes of early intervention for preterm infants and their parents: a randomized trial. Pediatrics 2016;138:e20161363. doi:10.1542/peds.2016-1363

63 Doyle LW. Victorian Infant Collaborative Study Group. Neonata intensive care at borderline viability-is it worth it?Early Hum Dev 2004;80:103-13. doi:10.1016/j.earlhumdev.2004.05.009.

64 Gallagher K, Martin J, Keller M, Marlow N. European variation in decision-making and parental involvement during preterm birth Arch Dis Child Fetal Neonatal Ed 2014;99:F245-9. doi:10.1136/ archdischild-2013-305191.

65 Janvier A, Lantos J. Delivery room practices for extremely preterm infants: the harms of the gestational age label. Arch Dis Child Fetal Neonatal Ed 2016;101:F375-6. doi:10.1136/ archdischild-2016-310466.

\section{Appendix: Supplementary materials}

